Solvent extraction studies for the separation of trivalent actinides from lanthanides with a triazole-functionalized 1,10-phenanthroline extractant

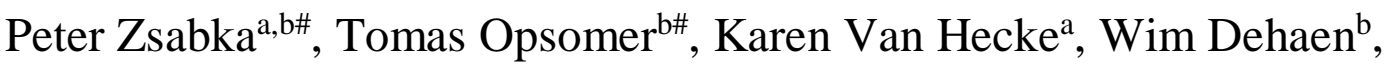
Andreas Wilden ${ }^{c}$, Giuseppe Modoloc, Marc Verwerft ${ }^{\mathrm{a}}$, Koen Binnemans ${ }^{\mathrm{b}}$, Thomas Cardinaels ${ }^{* a, b}$

${ }^{a}$ Belgian Nuclear Research Center (SCK CEN), Institute for Nuclear Materials Science, Boeretang 200, B-2400 Mol, Belgium; ${ }^{b} \mathrm{KU}$ Leuven, Department of Chemistry, Celestijnenlaan 200F, B-3001 Heverlee, Belgium; ' Forschungszentrum Jülich GmbH, Institut für Energie- und Klimaforschung, Nukleare Entsorgung und Reaktorsicherheit (IEK-6), 52428 Jülich, Germany.

\# Joint first authorship (authors contributed equally to this work).

*Email corresponding author: tcardina@sckcen.be 


\title{
Solvent extraction studies for the separation of trivalent actinides from lanthanides with a triazole-functionalized 1,10-phenanthroline extractant
}

\begin{abstract}
A new $N$-atom donor extractant 2,9-bis(1-(2-ethylhexyl)-1H-1,2,3-triazol-4-yl)1,10-phenanthroline (EH-BTzPhen) was synthesized and used in solvent extraction studies to separate the trivalent minor actinides americium(III) and curium(III) from europium(III), representing fission product lanthanides. The extractant was found to be soluble in 1-octanol and in the Aliquat-336 nitrate ([A336][ $\left[\mathrm{NO}_{3}\right]$ ) ionic liquid diluent, but insoluble in $n$-dodecane. The [A336] $\left[\mathrm{NO}_{3}\right]$ is a fully incinerable room temperature ionic liquid, and has a higher flash point than aliphatic diluents such as 1-octanol. The EH-BTzPhen proved to be effective for selective minor actinide extraction only in combination with 2-bromohexanoic acid synergist when 1-octanol was used as a diluent $\left(S F_{\mathrm{Am} / \mathrm{Eu}}>200\right)$. The change of the diluent from 1-octanol to Aliquat-336 nitrate allowed selective An(III) extraction from low acidity feed solutions without the need of a synergist $\left(S F_{\mathrm{Am} / \mathrm{Eu}} \sim 70\right.$ and $\left.S F_{\mathrm{Am} / \mathrm{Cm}} \sim 1.9-2.2\right)$. The phase transfer kinetics of the ligand-metal complexes is however very slow at $22{ }^{\circ} \mathrm{C}$ in the case of both solvents. With this newly synthesized extractant the achieved $S F_{\mathrm{Am} / \mathrm{Cm}}$ were comparable to the values achieved with the established $\mathrm{CyMe}_{4} \mathrm{BTBP}$ and $\mathrm{CyMe}_{4} \mathrm{BTPhen}$ extractants.
\end{abstract}

Keywords: Minor actinides, lanthanides, solvent extraction, Aliquat-336, ionic liquids, 1,2,3-triazole

\section{Introduction}

Minor actinides (neptunium, americium and curium) are responsible for the long-term heat emission and radiotoxicity of high level radioactive waste obtained after nuclear fuel reprocessing. Recycling of uranium and plutonium via the Plutonium Uranium Redox Extraction (PUREX) process is a mature technology applied on an industrial scale. ${ }^{1}$ The separation of neptunium is possible with a modification of the PUREX flow sheet. ${ }^{2,3}$ However, trivalent americium and curium are diverted to the 
highly active raffinate together with the other fission and corrosion products, because tri-n-butyl phosphate (TBP, the extractant used in the PUREX process), has no affinity towards the extraction of trivalent metal ions. The separate management or transmutation of americium and curium could allow for a more dense design of a deep underground final repository of conditioned high activity waste. ${ }^{4,5}$ However, curium would require excessive shielding and criticality control through all process stages of transmutation target fabrication due to its intensive neutron emission. Therefore, a partitioning and transmutation (P\&T) scenario would largely benefit from a robust and efficient chemical separation process to separate americium from curium and the lanthanides.

Soft-donor extractants using nitrogen or sulfur-based donor groups were found to be suitable for the separation of trivalent minor actinides from lanthanides. ${ }^{6-8}$ The tetradentate $N$-atom donor extractants 6,6'-bis(5,5,8,8- tetramethyl-5,6,7,8- tetrahydro1,2,4- benzotriazin -3-yl)-2,2'-bipyridine (CyMe $4 \mathrm{BTBP})^{9,} 1011-13$ and 2,9-bis(5,5,8,8tetramethyl-5,6,7,8- tetrahydro-1,2,4- benzotriazin -3-yl)-1,10- phenanthroline (CyMe$\left._{4} \mathrm{BTPhen}\right)^{14,15}$ are capable of extracting Am(III) and Cm(III) directly from highly active raffinate solutions. The metal-ligand interaction between the trivalent actinides $\mathrm{An}(\mathrm{III})$ and $\mathrm{CyMe}_{4} \mathrm{BTBP}$ or $\mathrm{CyMe}_{4} \mathrm{BTPhen}$ is possible due to the presence of four $\mathrm{N}$ atoms each having a lone electron pair in the metal-binding cavity (Figure1). Both compounds contain the six-membered triazinyl rings, where two of the donor lone electron pairs are softer nucleophiles than the lone pair of the pyridine-type $N$-atom of the 1,10-phenanthroline or 2,2'-bipyridine moiety. The increased nucleophilicity of the $\mathrm{N}$-atom in the 2-position in the triazinyl ring is caused by the lone pair of the adjacent non-coordinating $N$-atom at position 1 (so-called alpha effect). ${ }^{16-19}$ The excellent Am/Eu separation factors $\left(S F_{\mathrm{Am} / \mathrm{Eu}}=140\right.$ and $S F_{\mathrm{Am} / \mathrm{Eu}}=200-400$ for $\mathrm{CyMe}_{4} \mathrm{BTBP}$ and 
$\mathrm{CyMe}_{4} \mathrm{BTPhen}$, respectively) originate from the stronger covalent character of the An(III)-N bonds compared to Ln(III)-N bonds. ${ }^{7}$ At equilibrium, neither of these extractants show a high $\mathrm{Am} / \mathrm{Cm}$ separation factor $\left(S F_{\mathrm{Am} / \mathrm{Cm}} \approx 2.5\right.$ for $\mathrm{CyMe}_{4} \mathrm{BTBP}$ and CyMe ${ }_{4}$ BTPhen). ${ }^{11,14}$ When using the ionic liquid $[\mathrm{A} 336]\left[\mathrm{NO}_{3}\right]$ as diluent in combination with $\mathrm{CyMe}_{4} \mathrm{BTPhen}$ as extractant similar Am/Cm separation factors were observed at equilibrium and (much higher) separation factors were observed in nonequilibrium conditions. ${ }^{20}$ The ionic liquid $[\mathrm{A} 336]\left[\mathrm{NO}_{3}\right]$ was recently also tested in combination with the hard-donor extractant TODGA for the An(III) + Ln(III) coextraction from a simulated HAR solution and was found to be an interesting alternative to molecular diluents like $n$-dodecane. ${ }^{27}$ Moreover, TODGA was found to have a higher radiation stability in $[\mathrm{A} 336]\left[\mathrm{NO}_{3}\right]$ than in aliphatic diluents. ${ }^{28}$

The effect of replacing $2(1,2,4-)$ triazine moieties by $2(1,2,3-)$ triazole moieties in the case of the BTP complexants for An(III) and Ln(III) separation was demonstrated in the hydrophilic, tridentate complexant 2,6-bis[1-(propan-1-ol)-1,2,3-triazol-4-yl)]pyridine (PyTri-Diol). ${ }^{21,22}$ It proved to be a viable CHON-compliant alternative for the previously suggested $\mathrm{SO}_{3}-\mathrm{Ph}-\mathrm{BTP}$ molecule in the i-SANEX process. ${ }^{23,}{ }^{24}$ Similarly, a hydrophilic tetradentate 2,9-bis-(1H-1,2,3-triazol-4-yl)-1,10-phenanthroline complexant (BTrzPhen) was developed and tested with the purpose of Am(III)/(Cm(III)+Ln(III)) separation in an i-SANEX type process. ${ }^{25}$ The compound allowed a $S F_{\mathrm{Cm} / \mathrm{Am}}$ of 2.5 from a loaded $N, N, N^{\prime}, N^{\prime}$-tetra-n-octyl diglycolamide (TODGA) containing solvent. The achieved Eu(III)/Am(III) separation factors were lower by a factor of two than those achieved with PyTri-Diol. With both BTrzPhen and PyTri-Diol molecules, the increase of aqueous nitric acid concentration resulted in a loss of stripping efficiency, presumably be due to protonation of the extractants. 
Recently the synthesis and solvent extraction of the lipophilic, tetradentate 6,6'-bis(1(2-ethylhexyl)-1H-1,2,3-triazol-4-yl)-2,2'-bipyridine (EH-BTzBP) was reported. ${ }^{26}$ It was found that the extractant shows promising Am/Eu separation factors when used in combination with 2-bromohexanoic acid. The extraction properties of the novel extractant with respect to $\mathrm{Cm}(\mathrm{III})$ were not investigated.

For the present study, the unprecedented lipophilic 2,9-bis(1-(2-ethylhexyl)-1H-1,2,3triazol-4-yl)-1,10-phenanthroline (EH-BTzPhen) was synthesized (Figure 1). The extraction of An(III) and Ln(III) was studied using 1-octanol and Aliquat-336 nitrate ([A336] $\left[\mathrm{NO}_{3}\right]$ ) diluents. The purpose of this investigation was to study the extraction kinetics and selectivity of the extractant regarding Am(III), Cm(III), and Eu(III). The selectivity in solvent extraction is compared to the extractants with six-membered heterocycles. 


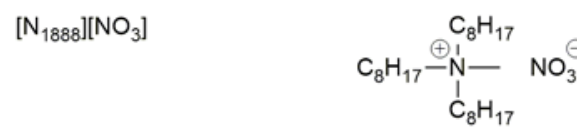

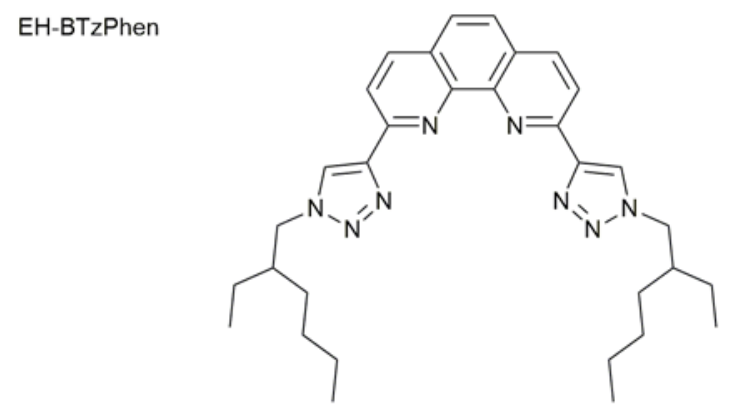

2-Bromohexanoic acid

$\mathrm{CyMe}_{4} \mathrm{BTPhen}$

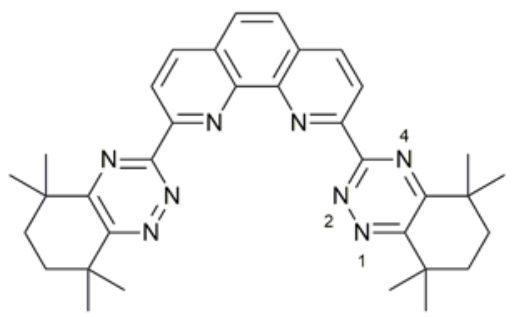

$\mathrm{CyMe}_{4} \mathrm{BTBP}$

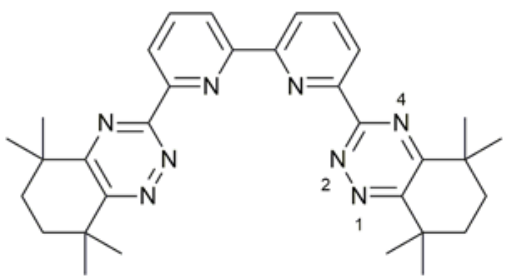

Figure 1. Chemical structures of the compounds used in this study. [A336] $\left[\mathrm{NO}_{3}\right]$ is represented by its main component, tri-n-octylmethylammonium nitrate $\left(\left[\mathrm{N}_{1888}\right]\left[\mathrm{NO}_{3}\right]\right)$. Two additional soft donor extractants, $\mathrm{CyMe}_{4} \mathrm{BTPhen}$ and $\mathrm{CyMe}_{4} \mathrm{BTBP}$ are represented to facilitate comparison of the structures. The numbering of nitrogen atoms in the triazynil rings are indicated for the sake of ease. 


\section{Experimental}

\subsection{Materials used for solvent extraction}

Aliquat ${ }^{\circledR} 336$ chloride ([A336][Cl], quaternary amine content: 88.2 - 90.6\%) of which the main component is tri-n-octylmethylammonium chloride ([N $\left.\left.\mathrm{N}_{1888}\right][\mathrm{Cl}]\right), 1$ octanol (purity > 99 \%), citric acid (purity > 99 \%), 2-bromohexanoic acid (purity 97 \%), silver(I) nitrate (purity: $99.9 \%$ ), ammonium nitrate (purity > $99 \%$ ), Dy $\left(\mathrm{NO}_{3}\right)_{3} \cdot 6 \mathrm{H}_{2} \mathrm{O}$ (purity: $99.9 \%$ ) and $\mathrm{Yb}\left(\mathrm{NO}_{3}\right)_{3} \cdot 5 \mathrm{H}_{2} \mathrm{O}$ (purity: 99.9 \%) were obtained from Sigma-Aldrich (Steinheim, Germany). Potassium nitrate (purity > $97.0 \%$ ), sodium nitrate (purity $>97.0 \%$ ) and sodium hydroxide (Titrisol) were obtained from Merck KGaA (Darmstadt, Germany). $\mathrm{Gd}\left(\mathrm{NO}_{3}\right)_{3} \cdot 6 \mathrm{H}_{2} \mathrm{O}$ (purity: $99.9 \%$ ) and $\mathrm{Eu}\left(\mathrm{NO}_{3}\right)_{3} \cdot 6 \mathrm{H}_{2} \mathrm{O}$ (purity: 99.99 \%) were obtained from Alfa Aesar GmbH (Karlsruhe, Germany). $\mathrm{La}\left(\mathrm{NO}_{3}\right)_{3} \cdot 6 \mathrm{H}_{2} \mathrm{O}$ (purity: $99.0 \%$ ) was obtained from Fluka Chemica (Seelze, Germany). $\operatorname{Pr}\left(\mathrm{NO}_{3}\right)_{3} \cdot 6 \mathrm{H}_{2} \mathrm{O}$ (purity: $99.9 \%$ ), $\mathrm{Nd}\left(\mathrm{NO}_{3}\right)_{3} \cdot 6 \mathrm{H}_{2} \mathrm{O}$ (purity: $99.9 \%$ ), $\mathrm{Sm}\left(\mathrm{NO}_{3}\right)_{3} \cdot 6 \mathrm{H}_{2} \mathrm{O}$ (purity: $99.9 \%$ ), $\mathrm{Y}\left(\mathrm{NO}_{3}\right)_{3} \cdot 6 \mathrm{H}_{2} \mathrm{O}$ (purity: $99.9 \%$ ) and $\mathrm{Ce}\left(\mathrm{NO}_{3}\right)_{3} \cdot 6 \mathrm{H}_{2} \mathrm{O}$ (purity: $99.9 \%$ ) were obtained from Strem Chemicals (Kehl, Germany). Trace metal grade nitric acid was obtained from Fischer Scientific Ltd. (Loughborough, UK). MilliQ water was used for all dilutions (resistivity: minimum $18.2 \mathrm{M} \Omega \mathrm{cm}$ ). ${ }^{241} \mathrm{Am}$ tracer in $1 \mathrm{~mol} \mathrm{~L}^{-1} \mathrm{HNO}_{3}$ solution (radiochemical purity > $99 \%$ ) was available from legacy stocks of SCK CEN. ${ }^{244} \mathrm{Cm}$ (radiochemical purity $>99.902 \%$ ) and ${ }^{152} \mathrm{Eu}$ (radiochemical purity $>99 \%$ ) radiotracers in $1 \mathrm{~mol} \mathrm{~L}^{-1} \mathrm{HNO}_{3}$ solutions were obtained from Eckert and Ziegler Nuclitec GmbH (Braunschweig, Germany).

The [A336][Cl] ionic liquid was converted into its nitrate form by a metathesis reaction by stirring $120 \mathrm{~mL}$ of [A336][Cl] with $120 \mathrm{~mL}$ of an aqueous solution of $2.5 \mathrm{~mol} \mathrm{~L}^{-1}$ $\mathrm{KNO}_{3}$ for 4 hours, followed by phase separation in a $1 \mathrm{~L}$ separation funnel. The 
equilibration and separation steps were repeated seven times until no AgCl precipitation was observed upon addition of drops of $\mathrm{AgNO}_{3}$ solution to the aqueous phase. After the metathesis reaction, the organic phase was washed three times with an equal volume of MilliQ water. The density of $[\mathrm{A} 336]\left[\mathrm{NO}_{3}\right]$ was determined with a density meter (Anton Paar DMA 4500 M), while the density of nitric acid solutions and nitrate solutions were taken from density tables.

\subsection{Synthesis of EH-BTzPhen}

All chemicals used for the synthesis of EH-BTzPhen were purchased from Acros Organics, Sigma Aldrich, Alfa Aesar and TCI Europe and used as received. For column chromatography, 70-230 mesh silica 60 (Acros) was used as the stationary phase. NMR spectra were recorded on a Bruker Avance III HD 400 spectrometer and chemical shifts $(\delta)$ are reported in parts per million (ppm) referenced to tetramethylsilane $\left({ }^{1} \mathrm{H}\right)$, or the internal (NMR) solvent signal $\left({ }^{13} \mathrm{C}\right)$. The high-resolution mass spectrum was acquired on a quadrupole orthogonal acceleration time-of-flight mass spectrometer (Synapt G2 HDMS, Waters, Milford, MA). The sample was infused at $3 \mu \mathrm{l} / \mathrm{min}$ and the spectrum was obtained in positive ionization mode with a resolution of 15000 (FWHM) using leucine enkephalin as lock mass. The melting point was determined on a MettlerToledo DSC 1 instrument, using a heating rate of $4{ }^{\circ} \mathrm{C} \min ^{-1}$ and under a helium atmosphere.

2,9-Diethynyl-1,10-phenanthroline was prepared in two steps from neocuproine, as described in the literature. ${ }^{25,29} \mathrm{EH}-\mathrm{BTzPhen}$ was synthesized according to a modified literature procedure using a copper-catalyzed azide-alkyne cycloaddition reaction (click-reaction) between the 2,9-diethynyl-1,10-phenanthroline and racemic 3(azidomethyl)heptane, dissolved in DCM (Scheme 1). ${ }^{30}$ 2,9-Diethynyl-1,10- 
phenanthroline (600 mg, $2.63 \mathrm{mmol}$ ) and racemic 3-(azidomethyl)heptane (939 mg, $6.05 \mathrm{mmol}$ ) were added to a $250 \mathrm{~mL}$ round-bottom flask and dissolved in $53 \mathrm{~mL}$ of dichloromethane (DCM). A solution of sodium ascorbate (1.042 g, $5.26 \mathrm{mmol})$ in $47 \mathrm{~mL}$ of water was added as a second phase. While stirring, a solution of $\mathrm{CuSO}_{4} \cdot 5 \mathrm{H}_{2} \mathrm{O}$ (13 mg, $0.053 \mathrm{mmol})$ and tris[(1-benzyl-1H-1,2,3-triazol-4-yl)methyl]amine (TBTA) (28 mg, $0.053 \mathrm{mmol}$ ) in $10.5 \mathrm{~mL}$ of $\mathrm{H}_{2} \mathrm{O}: \mathrm{DMSO}$ (1:1) was added slowly, followed by the addition of $N, N$-di-isopropylethylamine (DIPEA) (1.869 g, $14.46 \mathrm{mmol}$ ). The resulting mixture was stirred vigorously at room temperature for two days after which it was diluted with chloroform and washed with water (3x) and brine (1x). The organic layer was dried over $\mathrm{Na}_{2} \mathrm{SO}_{4}$ and concentrated. Next, the crude product was dissolved in diethyl ether and filtered. The filtrate was then concentrated and further purified via column chromatography on silica $\left(\mathrm{CHCl}_{3}: \mathrm{PrOH}\right.$ with gradient (1:0 to $\left.\left.19: 1\right)\right)$ to yield the pure product as an off-white solid (75 \% yield, $1.066 \mathrm{~g}$, mixture of stereoisomers). $M_{p}=147^{\circ} \mathrm{C}$.

$\left.{ }^{1} \mathrm{H} \mathrm{NMR} \mathrm{(CDCl} 3,400 \mathrm{MHz}\right): \delta=9.56$ (br s, 2H), 8.65 (d, $\left.J=8.4 \mathrm{~Hz}, 2 \mathrm{H}\right), 8.43$ (d, $J=$ $8.4 \mathrm{~Hz}, 2 \mathrm{H}), 7.92(\mathrm{~s}, 2 \mathrm{H}), 3.39-2.80(\mathrm{~m}, 4 \mathrm{H}), 1.26-1.10(\mathrm{~m}, 2 \mathrm{H}), 1.05-0.88$ (m, 4H), $0.83-0.29$ (m, 24H) (Figure S1). ${ }^{13} \mathrm{C} \mathrm{NMR}\left(\mathrm{CDCl}_{3}, 101 \mathrm{MHz}\right): \delta=151.69$, 147.92, 145.51, 137.24, 128.58, 126.36, 125.34, 120.67, 53.67, 39.23, 29.57, 27.93, 22.97, 22.81, 13.98, 9.98 (Figure S2).

HRMS (ESI-Q-TOF): $m / z[\mathrm{M}+\mathrm{H}]^{+}$calculated for $\mathrm{C}_{32} \mathrm{H}_{42} \mathrm{~N}_{8}$ : 539.3605; found: 539.3601. 

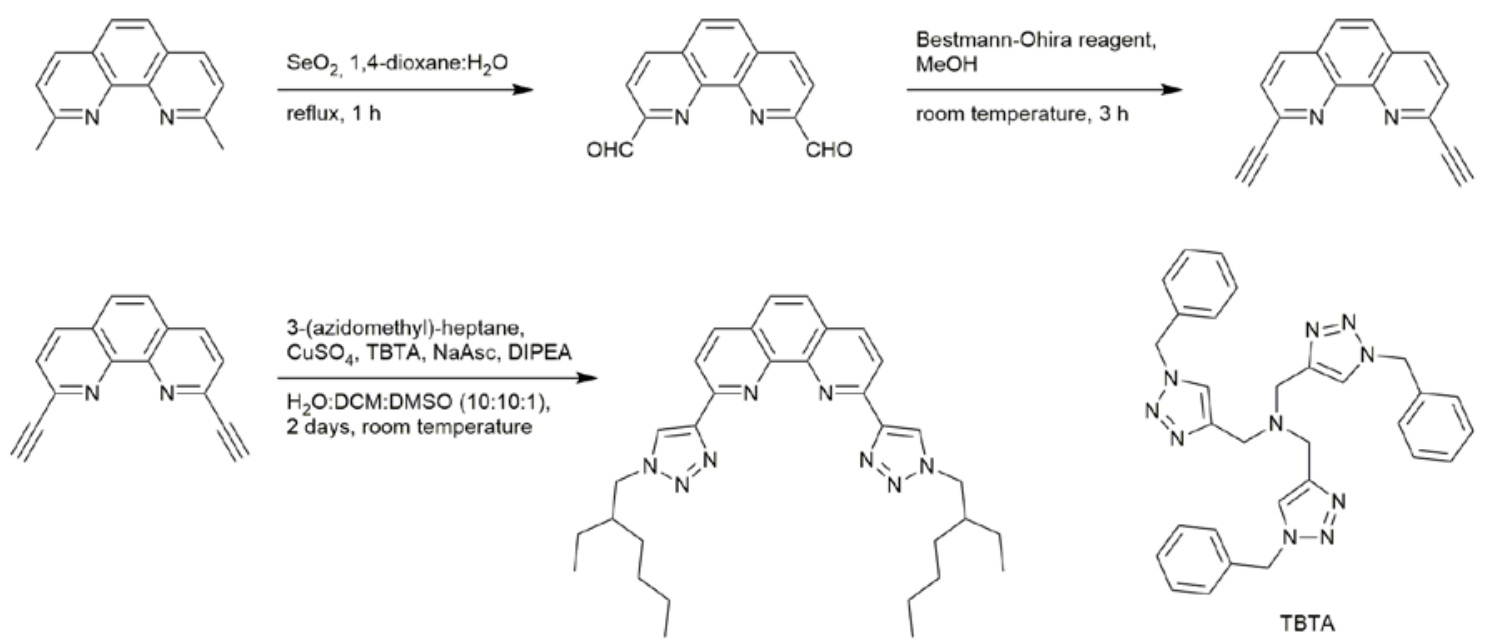

Scheme 1. Synthetic pathway towards EH-BTzPhen.

\subsection{Batch solvent extraction and analytical procedures}

Batch extraction studies were performed using $4 \mathrm{~mL}$ glass vials that fit into the boreholes of an in-house fabricated metal block mounted on a TMS-200 Thermoshaker (Nemus Life, Sweden). The temperature was controlled by the use of a cooling loop connected to a MC250 Microcool chiller (Lauda-Brinkmann, Germany).

A stock solution for the lanthanide-nitrate containing aqueous phases was prepared by dissolving the calculated amounts of trivalent nitrate salts of La, Ce, Pr, Nd, Sm, Eu, Gd, Dy, Yb and Y in $0.1 \mathrm{~mol} \mathrm{~L}^{-1} \mathrm{HNO}_{3}$ to obtain a $10^{-3} \mathrm{~mol} \mathrm{~L}^{-1}$ initial concentration of each $\mathrm{Ln}(\mathrm{III})$. From this stock solution $1 \mathrm{~mL}$ was taken for dilution to $100 \mathrm{~mL}$ in the desired final nitric acid concentration to obtain a final lanthanide concentration of $10^{-5}$ mol L-1 each. The exact nitric acid concentration of the stock solutions was determined by titration using an autotitrator (716 MPT Titrino, Metrohm Switzerland) filled with $0.1 \mathrm{~mol} \mathrm{~L}^{-1}$ or $0.01 \mathrm{~mol} \mathrm{~L}^{-1} \mathrm{NaOH}$ stock solution (Titrisol, Merck) or by measurement with a pH meter (691 pH meter, Metrohm, Switzerland). Spiked feed solutions were prepared by adding $3 \mathrm{kBq}$ (in $10 \mu \mathrm{L}$ volume) of each of the tracers ${ }^{241} \mathrm{Am},{ }^{152} \mathrm{Eu}$ and ${ }^{244} \mathrm{Cm}$ to $1 \mathrm{~mL}$ of the initial aqueous feed solution. All tracer-spiked aqueous feed 
solutions were prepared in advance and mixed thoroughly before contacting with the organic phase.

In a typical extraction experiment, $1 \mathrm{~mL}$ of the aqueous phase was mixed with an equal volume of pre-equilibrated organic phase and shaken at $22{ }^{\circ} \mathrm{C}$ at $2060 \mathrm{rpm}$ in a vial. The organic phase was pre-equilibrated with a nitric acid solution of the same acid concentration as used for the feed solution of the extraction step. After the equilibration, the phase disengagement was enhanced by centrifugation of the vials for 5 min at 4000 rpm using a Heraeus Labofuge 200 centrifuge. After phase separation, $300 \mu \mathrm{L}$ aliquots of the aqueous and organic phases were collected for gamma activity measurements.

Gamma spectrometric analysis of ${ }^{241} \mathrm{Am}$ (using the $59.5 \mathrm{keV} \gamma$-peak) and ${ }^{152} \mathrm{Eu}$ (using the $121.8 \mathrm{keV}, 344 \mathrm{keV}, 778.9 \mathrm{keV}, 964 \mathrm{keV}, 1112 \mathrm{keV}$ and $1408 \mathrm{keV} \gamma$-peaks) was performed using a HPGe detector (Canberra Semiconductors N. V., Olen, Belgium) with Genie2000 software. The activities of $\alpha$-particle emitting radionuclides in each separated phase were determined using $\alpha$ spectroscopy. Weighed amounts of the organic or aqueous phases were pipetted on a cupped steel planchet, heated under an infrared lamp (Theratherm $150 \mathrm{~W}$, Osram, Germany) and subsequently burned in using a gas torch. The ${ }^{241} \mathrm{Am}\left(E_{\alpha}=5.485 \mathrm{MeV}\right)$ and ${ }^{244} \mathrm{Cm}\left(E_{\alpha}=5.805 \mathrm{MeV}\right)$ alpha peaks were measured using an $\alpha$ spectrometer (Alpha Analyst, Canberra) equipped with Passivated Implanted Planar Silicon (PIPS) $\alpha$ detectors (Canberra Olen N.V., Olen, Belgium). The spectra were analyzed using Apex Alpha software.

The distribution ratio $(D)$ of a given analyte was calculated as the ratio of the concentration of the analyte present in the organic phase over the concentration present in the aqueous phase in accordance with Equation (1). 


$$
D_{M}=\frac{\left[M_{\text {org.eq. }}\right]}{\left[M_{\text {aq.eq. }}\right]}
$$

The highest and lowest distribution ratio limits for ${ }^{241} \mathrm{Am}$ and ${ }^{244} \mathrm{Cm}$ determined by the $\alpha$ spectrometry detection limits in the aqueous or organic phases were 1000 and 0.001 , respectively. $\gamma$ spectrometry allowed the determination of distribution ratios for ${ }^{241} \mathrm{Am}$ between 200 and 0.05 and between 1000 and 0.001 for ${ }^{152} \mathrm{Eu}$.

The separation factor (SF) of two elements was calculated from the distribution ratios of the respective elements in accordance with Equation (2):

$$
S F=\frac{D_{M x}}{D_{M y}}
$$

\section{Results and discussion}

Solubility tests were conducted on the freshly synthesized extractant. The solubility of the extractant was lower than $0.01 \mathrm{~mol} \mathrm{~L}^{-1}$ in $n$-dodecane, resulting in a slurry with most of the compound left undissolved. It also shows to be insoluble in pentane, hexane and heptane. The $\pi-\pi$ stacking of the planar phenanthroline groups of EH-BTzPhen molecules might be a reason for the preferred crystallization over solubilisation in aliphatic diluents. The extractant proved to be soluble in various polar diluents; 1-octanol (up to $0.2 \mathrm{~mol} \mathrm{~L}^{-1}$ ) and the ionic liquid [A336] $\left[\mathrm{NO}_{3}\right.$ ] (up to $0.2 \mathrm{~mol}$ $\mathrm{L}^{-1}$ ). The compound showed a high solubility (during the synthesis and purification steps) in dichloromethane, chloroform and diethylether. In contrast to our EH-BTzPhen, the tridentate 2,6-Bis[1-(2-ethylhexyl)-1H-1,2,3-triazol-4-yl]pyridine (PTEH), carrying identical moieties was highly soluble both in apolar kerosene as well as polar DCM and 1-octanol. ${ }^{31}$ For solvent extraction studies, $0.01 \mathrm{~mol} \mathrm{~L}^{-1}$ solutions of the EH-BTZPhen in both 1-octanol and in Aliquat-336 nitrate ionic liquid were used. Scoping studies were performed to test the compatibility of the extractant in these two diluents with an 
acidic aqueous phase. $1 \mathrm{~mol} \mathrm{~L}^{-1}, 0.75 \mathrm{~mol} \mathrm{~L}^{-1}$ and $0.5 \mathrm{~mol} \mathrm{~L}^{-1} \mathrm{HNO}_{3}$ resulted in the formation of a white precipitate in the case of both solvents, which did not dissolve after several weeks. With $0.1 \mathrm{~mol} \mathrm{~L}^{-1} \mathrm{HNO}_{3}$ the organic phase remained clear, however a small amount of opaque layer was formed at the interphase. Protonation of the nitrogen atoms in the second or third position of triazole rings and subsequent inter-molecular $H$ bond formation can be a plausible reason for the observed precipitation. The unsubstituted $1 H$-1,2,3-triazole is a stronger base $\left(\mathrm{pK}_{\mathrm{a}}=1.17\right)^{32}$ than the $1,2,4$ triazine $\left(\mathrm{pK}_{\mathrm{a}}<0\right)$. In comparison to EH-BTzPhen, neither CyMe $4 \mathrm{BTBP}$, nor $\mathrm{CyMe}_{4} \mathrm{BTPhen}$ (both containing triazines) show acid-induced precipitation when their organic solutions are contacted with acidic aqueous phases. The acid-induced precipitation of EHBTzPhen is a marked contrast with the result of the acid stability test using $1 \mathrm{~mol} \mathrm{~L}^{-1}$ $\mathrm{HNO}_{3}$ performed by Muller and Nash on EH-BTzBP in toluene. ${ }^{26}$ The structural difference between the two compounds is the cis-locked conformation of the 1,10phenanthroline moiety compared to the 2,2'-bipyridine unit. Contact of organic solutions of EH-BTzPhen with aqueous phases at lower acidities ( $\mathrm{pH} 2-3)$ did not result in the formation of precipitates. Solvent extraction studies were conducted only at these $\mathrm{pH}$ values to prevent precipitation.

Since the structurally similar EH-BTzBP molecule was previously tested in a molecular diluent, we also tested our new cis-locked EH-BTzPhen in 1-octanol. ${ }^{26}$ This scoping solvent extraction study did not result in extraction of ${ }^{241} \mathrm{Am}(\mathrm{III}),{ }^{244} \mathrm{Cm}$ (III) and ${ }^{152} \mathrm{Eu}(\mathrm{III})$ from $1 \mathrm{~mol} \mathrm{~L}^{-1} \mathrm{NH}_{4} \mathrm{NO}_{3}$ aqueous feed solution with $0.01 \mathrm{~mol} \mathrm{~L}^{-1} \mathrm{EH}-$ BTzPhen in 1-octanol: $D_{\mathrm{Am}}=(0.25 \pm 0.04), D_{\mathrm{Eu}}=(0.094 \pm 0.001)$. It is known that some soft $N$-atom donor extractants are able to extract the metal nitrates directly from acidic feed solutions without the need for a synergist. The formerly mentioned 
$\mathrm{CyMe}_{4} \mathrm{BTBP}$ and $\mathrm{CyMe}_{4} \mathrm{BTPhen}$ are examples of such tetradentate extractants. The tridentate 2,6-bis[1-(2-ethylhexyl)-1H-1,2,3-triazol-4yl]pyridine (PTEH) (in a solution of $0.2 \mathrm{~mol} \mathrm{~L}^{-1}$ in kerosene/1-octanol mixture) was able to extract Am(III) selectively $\left(S F_{\mathrm{Am} / \mathrm{Eu}} \sim 80\right)$ without the addition of a synergist. ${ }^{31}$

However, some other $N$-atom donor extractants, like the tetradentate EH-BTzBP are not able to stabilize the metal nitrates in an aliphatic organic phase, but extraction is possible with the use of a lipophilic anion source. ${ }^{26}$ Therefore, the addition of 2bromohexanoic acid as a lipophilic anion source was tested with the present EHBTzPhen extractant (Figure 2). Speciation studies of Eu(III) complexes with EHBTzBP using time-resolved laser-fluorescence spectroscopy (TRLFS) did not show the presence of bromohexanoate anions in the first coordination sphere. ${ }^{35}$ Therefore, it is assumed that bromohexanoate anions act as outer-sphere anions for charge compensation in the organic phase. Figure 2 shows that the extraction kinetics of 0.01 mol L ${ }^{-1}$ EH-BTzPhen $+1 \mathrm{~mol} \mathrm{~L}^{-1}$ 2-bromohexanoic acid in 1-octanol is slow. The equilibrium distribution ratios were reached in $24 \mathrm{~h}$ for ${ }^{241} \mathrm{Am}$ (III) and ${ }^{244} \mathrm{Cm}$ (III) and within $12 \mathrm{~h}$ for ${ }^{152} \mathrm{Eu}(\mathrm{III})$. Equilibrium distribution ratios were (400 \pm 100$)$ for ${ }^{241} \mathrm{Am}(\mathrm{III}),(190 \pm 50)$ for ${ }^{244} \mathrm{Cm}(\mathrm{III})$ and $(1.7 \pm 0.2)$ for ${ }^{152} \mathrm{Eu}(\mathrm{III})$.

The solvent extraction mechanism for the EH-BTzBP/bromohexanoic acid/toluene solvent was suggested to be best described as a cation exchange between the acidic protons of 2-bromohexanoic acid and the trivalent metal ions and we assume a similar mechanism for the EH-BTzPhen analogue (Equation (3)). ${ }^{26}$

$$
\begin{aligned}
& \mathrm{M}^{3+}{ }_{\text {(aq.) }}+2 \text { EH-BTzPhen }(\text { org. }) \\
& M(\text { EH-BTzPhen })_{2} \mathrm{~A}_{3}(\mathrm{HA})_{3(\text { org. })}+3 \mathrm{H}_{2, \text { (org. })}{ }_{(\text {aq. })}
\end{aligned}
$$

Where HA represents 2-bromohexanoic acid. 


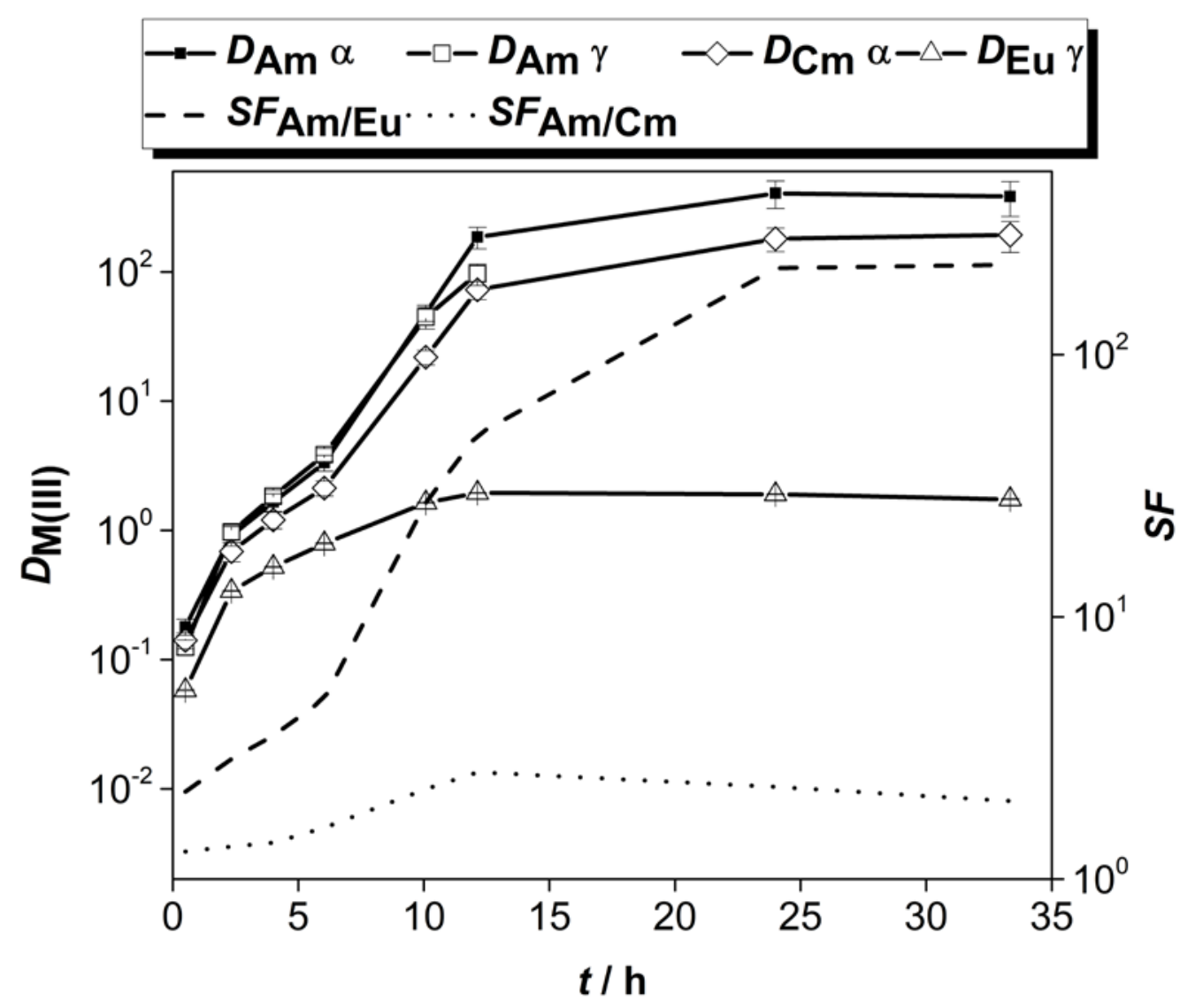

Figure 2. Distribution ratios of $\mathrm{Am}(\mathrm{III}), \mathrm{Cm}(\mathrm{III})$ and $\mathrm{Eu}(\mathrm{III})$ and $\mathrm{Am} / \mathrm{Eu}$ and $\mathrm{Am} / \mathrm{Cm}$ separation factors as a function of equilibration time. Extraction conditions: $T=22 \pm 1$ ${ }^{\circ} \mathrm{C}$; 2060 rpm; a/o = 1/1; organic phase $0.01 \mathrm{~mol} \mathrm{~L}^{-1}$ EH-BTzPhen $+1 \mathrm{~mol} \mathrm{~L}^{-1}$ 2-bromohexanoic acid in 1-octanol, Aqueous phase: $\mathrm{pH}=3$; $1 \mathrm{~mol} \mathrm{~L}^{-1} \mathrm{NH}_{4} \mathrm{NO}_{3}$, $[\operatorname{Ln}(\mathrm{III})]=10^{-5} \mathrm{~mol} \mathrm{~L}^{-1}$ each.

The use of 2-bromohexanoic acid would be difficult in nuclear fuel cycle applications as the introduction of high concentrations of bromine in the organic solvent is a disadvantage from the point of view of secondary waste treatment. Furthermore, radiation induced degradation would most probably liberate highly corrosive bromine from such a solvent.

Figure 3 shows the distribution ratios of ${ }^{241} \mathrm{Am}(\mathrm{III}),{ }^{244} \mathrm{Cm}(\mathrm{III})$ and ${ }^{152} \mathrm{Eu}(\mathrm{III})$ for batch liquid-liquid extraction experiments using feed solutions with $[\mathrm{Ln}(\mathrm{III})]=10^{-5} \mathrm{~mol} \mathrm{~L}^{-1}$, 
$\mathrm{pH}=3$ and $1 \mathrm{~mol} \mathrm{~L}^{-1} \mathrm{NH}_{4} \mathrm{NO}_{3}$ and an organic phase composed of $0.01 \mathrm{~mol} \mathrm{~L}^{-1} \mathrm{EH}-$ BTzPhen in [A336] $\left[\mathrm{NO}_{3}\right]$ as a function of equilibration time. Kinetic experiments were conducted until $110 \mathrm{~h}$, after which the Am(III) distribution values reached equilibrium, while distribution ratios of ${ }^{244} \mathrm{Cm}(\mathrm{III})$ and ${ }^{152} \mathrm{Eu}(\mathrm{III})$ still slightly increased. Such an extremely slow extraction is not advantageous in a continuous solvent extraction process, as it would require the design of a plant with large footprint and cost. The solvent radiolysis and equipment wear would also be more important in case of very long contact times. However, it is shown in our recent study using the $\mathrm{CyMe}_{4} \mathrm{BTPhen}$ complexant in $[\mathrm{A} 336]\left[\mathrm{NO}_{3}\right]$ that the slow kinetics can be significantly improved by increasing the temperature. ${ }^{20}$ The time needed to reach the equilibrium is more dependent on factors affecting diffusion of species to and from the interphase. By comparing the kinetics of $\mathrm{CyMe}_{4} \mathrm{BTPhen}$ in $[\mathrm{A} 336]\left[\mathrm{NO}_{3}\right]$ under comparable conditions as used in this study, we hypothesize that the high viscosity of the ionic liquid cannot be alone the reason.

Figure 3. Distribution ratios of $\mathrm{Am}(\mathrm{III}), \mathrm{Cm}(\mathrm{III})$ and $\mathrm{Eu}(\mathrm{III})$ and $\mathrm{Am} / \mathrm{Eu}$ and $\mathrm{Am} / \mathrm{Cm}$ separation factors as a function of equilibration time. Extraction conditions: $T=22 \pm 1$ ${ }^{\circ} \mathrm{C}$; $2060 \mathrm{rpm}$; a/o = 1/1; organic phase $0.01 \mathrm{~mol} \mathrm{~L}{ }^{-1} \mathrm{EH}-\mathrm{BTzPhen}$ in [A336][NO $\mathrm{NO}_{3}$, Aqueous phase: $\mathrm{pH}=3 ; 1 \mathrm{~mol} \mathrm{~L}^{-1} \mathrm{NH}_{4} \mathrm{NO}_{3}$, [Ln(III) $]=10^{-5} \mathrm{~mol} \mathrm{~L}^{-1}$ each. The $D_{\text {Eu }}$ at 8 $\mathrm{h}$ is likely to be an outlier data point. 


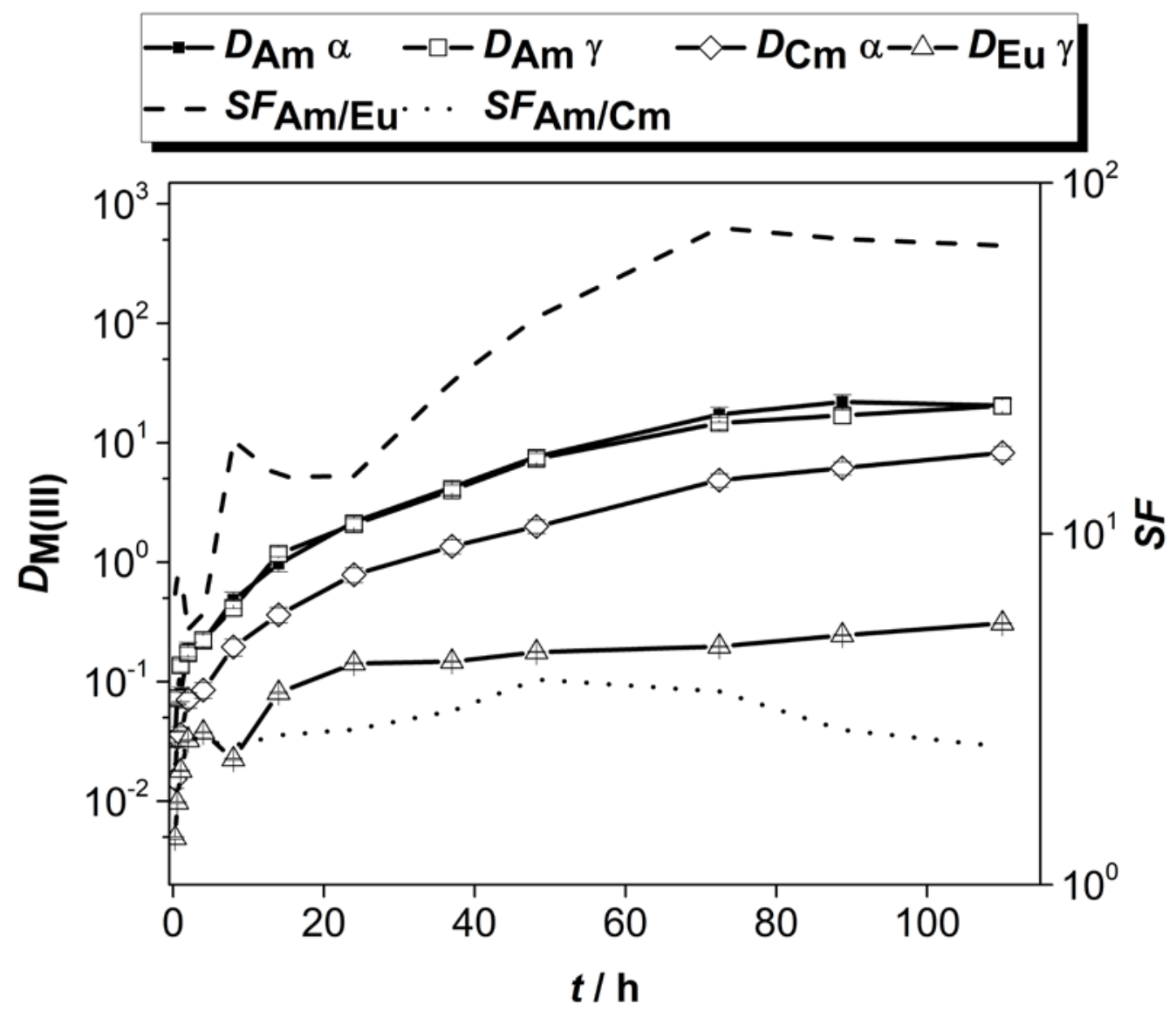

Figure 3. Distribution ratios of $\mathrm{Am}(\mathrm{III}), \mathrm{Cm}(\mathrm{III})$ and $\mathrm{Eu}(\mathrm{III})$ and $\mathrm{Am} / \mathrm{Eu}$ and $\mathrm{Am} / \mathrm{Cm}$ separation factors as a function of equilibration time. Extraction conditions: $T=22 \pm 1$ ${ }^{\circ} \mathrm{C}$; $2060 \mathrm{rpm} ; \mathrm{a} / \mathrm{o}=1 / 1$; organic phase $0.01 \mathrm{~mol} \mathrm{~L}{ }^{-1} \mathrm{EH}-\mathrm{BTzPhen}$ in [A336][NO 3 , Aqueous phase: $\mathrm{pH}=3 ; 1 \mathrm{~mol} \mathrm{~L}^{-1} \mathrm{NH}_{4} \mathrm{NO}_{3}$, $[\mathrm{Ln}(\mathrm{III})]=10^{-5} \mathrm{~mol} \mathrm{~L}^{-1}$ each. The $D_{\text {Eu }}$ at 8 $\mathrm{h}$ is likely to be an outlier data point.

We assume the reason for significantly slower kinetics of An(III) extraction by EHBTzPhen as compared to $\mathrm{CyMe}_{4} \mathrm{BTPhen}$ is linked to the higher basicity of the 1,2,3triazole rings compared to 1,2,4 triazines. Even when the acid concentration in the organic phase is not sufficient to cause a complete aggregation of the protonated EHBTzPhen molecules (manifesting in visible precipitation) there might be a lower degree of association/supramolecular organization caused by an intermolecular $H$-bond 
network. In that case, not the single EH-BTzPhen molecules are the diffusing entities, but larger number of them, held together by a $H$-bond network. In liquids, according to the Stokes-Einstein equation the radius of the diffusing entity is inversely proportional to the diffusion coefficient. Thus the increase of diffusion coefficient of the extractant, caused by association via $H$-bonds can be the reason for the observed slow extraction kinetics.

The distribution ratios for ${ }^{241} \mathrm{Am}(\mathrm{III})$ and ${ }^{244} \mathrm{Cm}$ (III) reached values up to $D_{\mathrm{Am}}=(20 \pm 3)$, $D_{\mathrm{Cm}}=(8 \pm 1)$, respectively, while ${ }^{152} \mathrm{Eu}(\mathrm{III})$ distribution ratios reached values up to $D_{\mathrm{Eu}}=$ (0.307 \pm 0.003$)$. This is a factor of about 20 lower for An(III) and a factor of 6 lower for ${ }^{152} \mathrm{Eu}(\mathrm{III})$ compared to the 1-octanol diluent. In addition, the ${ }^{241} \mathrm{Am}(\mathrm{III}) /{ }^{152} \mathrm{Eu}(\mathrm{III})$ separation factors were lower in the case of the ionic liquid based solvent $\left(S F_{\mathrm{Am} / \mathrm{Eu}} \sim 70\right.$ compared to $S F_{\mathrm{Am} / \mathrm{Eu}} \sim 200$ in 1-octanol). These separation factors are similar to the one reported by Muller and Nash using EH-BTzBP in combination with 2-bromohexanoic acid in toluene. ${ }^{26}$

The equilibrium ${ }^{241} \mathrm{Am}(\mathrm{III}) /{ }^{152} \mathrm{Eu}(\mathrm{III})$ separation factor of $S F_{\mathrm{Am} / \mathrm{Eu}} \approx(70 \pm 20)$ reached promising values for a minor actinide separation process. These distribution ratios are significantly lower, compared to those obtained with $0.01 \mathrm{~mol} \mathrm{~L}^{-1} \mathrm{CyMe}_{4} \mathrm{BTPhen}$ in [A336][NO 3$]: D_{\mathrm{Am}}(1000 \pm 250), D_{\mathrm{Cm}} \sim(670 \pm 160), D_{\mathrm{Eu}}=(9.9 \pm 0.2)$, while the Am/Eu separation factor is similar: $S F_{\mathrm{Am} / \mathrm{Eu}}=(100 \pm 30)$. The lower distribution ratios in general might be an advantage for back-extraction of the An(III) from the loaded organic phase. The ${ }^{241} \mathrm{Am}(\mathrm{III}) /{ }^{244} \mathrm{Cm}(\mathrm{III})$ separation factor was between 2.1 - 3.5 throughout the investigated contact time (Figure 3), thus slightly higher than in the case of the first solvent (0.01 mol L $\mathrm{m}^{-1} \mathrm{EH}-\mathrm{BTzPhen}$ and $1 \mathrm{~mol} \mathrm{~L}^{-1}$ 2-bromohexanoic acid in 1-octanol). The change of the triazinyl rings to 1,2,3-triazolyl rings thus lead to a slight increase of 
$\mathrm{Am}(\mathrm{III}) / \mathrm{Cm}(\mathrm{III})$ separation factors compared to $\mathrm{CyMe}_{4} \mathrm{BTPhen}$ extractant in [A336] $\left[\mathrm{NO}_{3}\right]$ which typically shows a $S F_{\mathrm{Am} / \mathrm{Cm}} 1.4-1.8$ at equilibrium and higher values under non-equilibrium conditions. In the case of EH-BTzPhen, it seems no such difference exists between the $S F_{\mathrm{Am} / \mathrm{Cm}}$ at shorter or longer extraction times. From this it is hypothesized, that the higher $S F_{\mathrm{Am} / \mathrm{Cm}}$ are related to the slightly stronger interaction between the triazole donating $N$-atoms and Am(III) as compared to the interaction with Cm(III).

The effect of $\mathrm{NH}_{4} \mathrm{NO}_{3}$ concentration on the distribution ratios of ${ }^{241} \mathrm{Am}(\mathrm{III}),{ }^{244} \mathrm{Cm}(\mathrm{III})$ and ${ }^{152} \mathrm{Eu}(\mathrm{III})$ was tested at $110 \mathrm{~h}$ equilibration time (Figure 4). The distribution ratios increased with increasing $\mathrm{NH}_{4} \mathrm{NO}_{3}$ concentration. In general, the ${ }^{241} \mathrm{Am}(\mathrm{III}) /{ }^{152} \mathrm{Eu}(\mathrm{III})$ and ${ }^{241} \mathrm{Am}(\mathrm{III}) /{ }^{244} \mathrm{Cm}$ (III) selectivity remained constant over the range of $\mathrm{NH}_{4} \mathrm{NO}_{3}$ concentration (disregarding some fluctuations that are presumably caused by measurement uncertainties). The increase of distribution ratios as a function of the nitrate concentration suggests that nitrate ions are serving as counter ions in the extracted complex. The exact extraction mechanism cannot be determined solely on the basis of solvent extraction experiments. The slope analysis suggest increasing nitrate stoichiometric numbers as a function of the increase of nitrate concentrations as the slope for $\log D$ vs. $\log \left[\mathrm{NO}_{3}\right]^{-}$increased with increasing $\mathrm{NH}_{4} \mathrm{NO}_{3}$ concentration. However, the slope analysis method is considered to be limited here, as a progressive deviation of the activity coefficients from 1 is expected as a function of increase of ammonium nitrate concentration. 


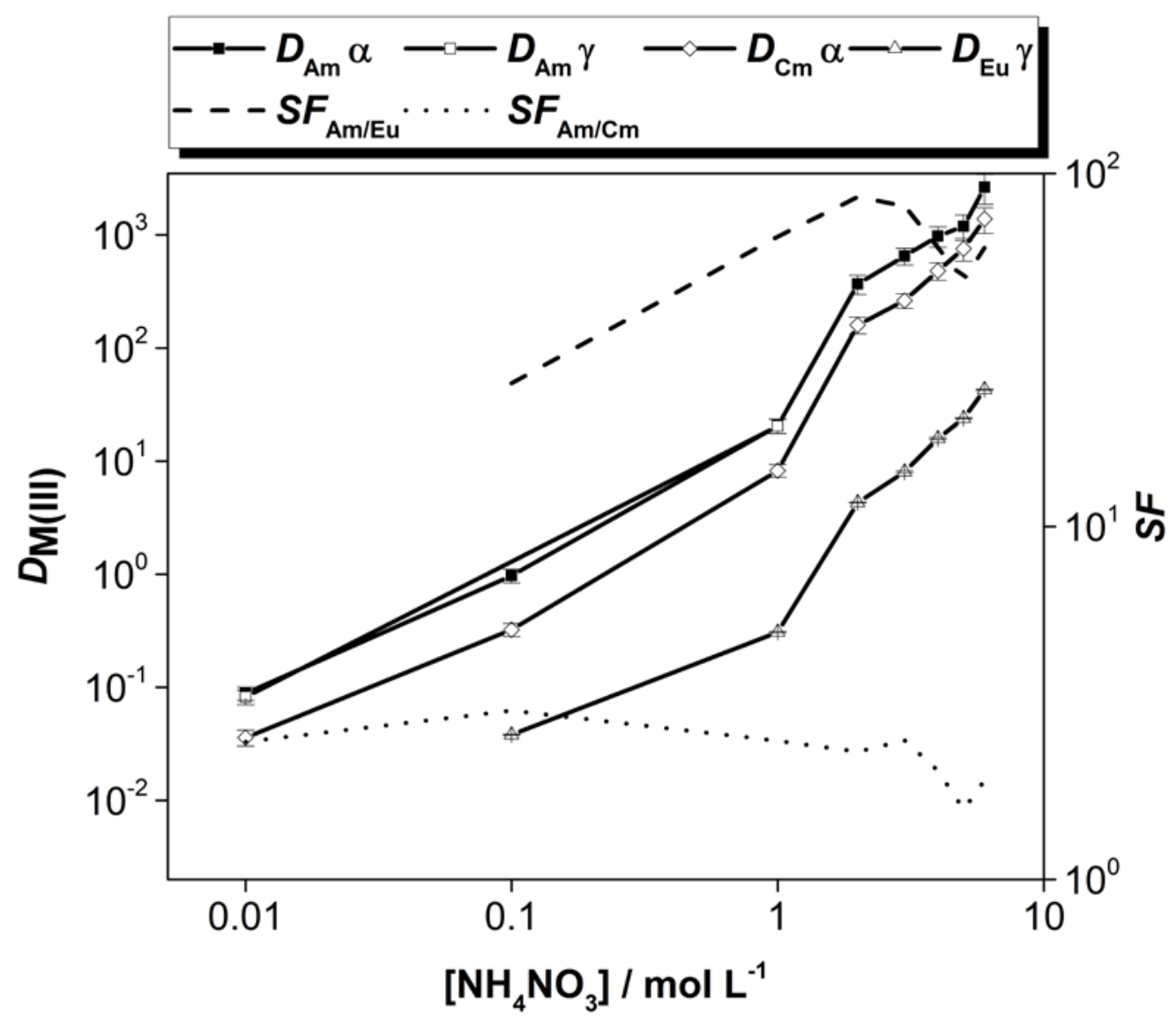

Figure 4. Distribution ratios of $\mathrm{Am}(\mathrm{III}), \mathrm{Cm}(\mathrm{III})$ and $\mathrm{Eu}(\mathrm{III})$ and $\mathrm{Am} / \mathrm{Eu}$ and $\mathrm{Am} / \mathrm{Cm}$ separation factors as a function of nitrate ion concentration. Extraction conditions: $T=$ $22 \pm 1^{\circ} \mathrm{C}$; $2060 \mathrm{rpm} ; t=110 \mathrm{~h} ; \mathrm{a} / \mathrm{o}=1 / 1$; organic phase $0.01 \mathrm{~mol} \mathrm{~L}^{-1} \mathrm{EH}-\mathrm{BTzPhen}$ in [A336] $\left[\mathrm{NO}_{3}\right]$, Aqueous phase: $\mathrm{pH}=3$; various concentration of $\mathrm{NH}_{4} \mathrm{NO}_{3},[\mathrm{Ln}(\mathrm{III})]=$ $10^{-5} \mathrm{~mol} \mathrm{~L}^{-1}$ each.

In our efforts to develop a new, more performant tetradentate $\mathrm{N}$-donor extractant molecule, the EH-BTzPhen was synthesized and subject to basic solvent extraction screening. During these screening studies the molecule displayed unfortunately important disadvantages, such as incompatibility with higher nitric acid concentrations and very slow extraction kinetics, indicating that its application in continuous processes will not be feasible using the investigated solvent composition and extraction 
parameters. Therefore, more advanced extractions studies (e.g. effect of acidity, temperature, ligand concentration) were not relevant and thus not performed. Notwithstanding these disadvantages, the interesting ${ }^{241} \mathrm{Am}(\mathrm{III}) /{ }^{244} \mathrm{Cm}(\mathrm{III})$ and ${ }^{241} \mathrm{Am}(\mathrm{III}) /{ }^{152} \mathrm{Eu}(\mathrm{III})$ separation factors supports further work on triazole-modified phenanthrolines to overcome the current issues.

\section{Conclusions}

As conclusion, the newly synthesized lipophilic tetradentate, CHON-compliant soft-donor extractant EH-BTzPhen was found to provide interesting selectivity for An(III) over Eu(III) at low acidities. The compound is soluble in both 1-octanol and [A336] $\left[\mathrm{NO}_{3}\right]$. The extraction of Am(III) and Cm(III) was possible in 1-octanol with the combined use of 2-bromohexanoic acid synergist. When [A336] $\left[\mathrm{NO}_{3}\right]$ is used as diluent, extraction of An(III) is feasible without the presence of synergist, although with slow extraction kinetics at $22{ }^{\circ} \mathrm{C}$. The extractant formed a precipitate in contact with highly acidic feed solutions, and as a consequence, it is not suitable to separate minor actinides directly from a PUREX raffinate without prior adjustment of the acidity. The modulation of the electron density on two of the nitrogen atoms in the complexing cavity (e.g. by replacing 1,2,4-triazinyl with 1,2,3-triazole moieties) of CyMe${ }_{4} \mathrm{BTPhen}$ retained the $\mathrm{Am} / \mathrm{Cm}$ and $\mathrm{Am} / \mathrm{Eu}$ selectivities, but at lower distribution ratios. Lower distribution ratios mean that for quantitative extraction a higher number of stages are necessary, but it is beneficial for back-extraction, which might be exploited in further work involving modified 5-membered heterocycle moieties crafted on bipyridine or phenanthroline backbone. The use of CHON-compatible, non-flammable [A336][ $\left.\mathrm{NO}_{3}\right]$ as a diluent for the EH-BTzPhen allowed the extraction of An(III) ions without the addition of a synergist. This latter finding might be of interest for further research on 
complexants that proved to be effective only in the presence of 2-bromohexanoic acid or similar synergists.

\section{Acknowledgements:}

The authors would like to thank Magda Ooms for the help with the alpha spectrometry measurements.

\section{Funding details:}

P.Zs. acknowledges the SCK CEN for providing funding for a PhD fellowship and the FOD Economie for providing additional support (Energietransitiefonds).

T.O. is a doctoral fellow of FWO Vlaanderen $(1154419 N)$. Mass spectrometry was made possible by the support of the Hercules Foundation of the Flemish Government (grant 20100225-7).

\section{Supplemental online material}

Supplementary data $\left[{ }^{1} \mathrm{H}\right.$ and ${ }^{13} \mathrm{C}$-NMR spectra of the EH-BTzPhen] are available online.

\section{References}

1. $\quad$ H. H. Anderson and L. B. Asprey, US Pat. 2,924,506, 1960.

2. R. J. Taylor, C. R. Gregson, M. J. Carrott, C. Mason and M. J. Sarsfield, Solv. Extr. Ion Exch., 2013, 31, 442-462.

3. H. Chen, R. J. Taylor, M. Jobson, D. A. Woodhead, C. Boxall, A. J. Masters and S. Edwards, Solv. Extr. Ion Exch., 2017, 35, 1-18.

4. C. Poinssot, S. Bourg, S. Grandjean and B. Boullis, Procedia Chem., 2016, 21, 536-544.

5. D. Greneche, B. Quiniou, L. Boucher, M. Delpech, E. Gonzalez, F. Alvarez, M. A. Cuñado, G. Serrano, J. L. Cormenzana, W. Kuckshinrichs, R. Odoj, W. von Lensa, J. Wallenius, D. Westlén, C. Zimmermann and J. Marivoet, REDIMPACT Impact of Partitioning, Transmutation and Waste Reduction Technologies on the Final Nuclear Waste Disposal, Forschungszentrum Jülich 
GmbH Institut für Energieforschung (IEF) Sicherheitsforschung und Reaktortechnik (IEF-6), Jülich, Germany, 2008.

6. $\quad$ P. J. Panak and A. Geist, Chem. Rev., 2013, 113, 1199-1236.

7. $\quad$ F. W. Lewis, M. J. Hudson and L. M. Harwood, Synlett, 2011, 18, 2609-2632.

8. Z. Kolarik, Chem. Rev, 2008, 108, 4208-4252.

9. M. G. B. Drew, M. R. S. J. Foreman, A. Geist, M. J. Hudson, F. Marken, V. Norman and M. Weigl, Polyhedron, 2006, 25, 888-900.

10. A. Geist, C. Hill, G. Modolo, M. R. S. J. Foreman, M. Weigl, K. Gompper and M. J. Hudson, Solv. Extr. Ion Exch., 2006, 24, 463-483.

11. A. Wilden, C. Schreinemachers, M. Sypula and G. Modolo, Solv. Extr. Ion Exch., 2011, 29, 190-212.

12. D. Magnusson, B. Christiansen, M. R. S. Foreman, A. Geist, J. P. Glatz, R. Malmbeck, G. Modolo, D. Serrano-Purroy and C. Sorel, Solv. Extr. Ion Exch., 2009, 27, 97-106.

13. M. G. B. Drew, M. R. S. J. Foreman, C. Hill, M. J. Hudson and C. Madic, Inorg. Chem. Commun., 2005, 8, 239-241.

14. F. W. Lewis, L. M. Harwood, M. J. Hudson, M. G. Drew, J. F. Desreux, G. Vidick, N. Bouslimani, G. Modolo, A. Wilden, M. Sypula, T. H. Vu and J. P. Simonin, J. Am. Chem. Soc., 2011, 133, 13093-13102.

15. S. Lange, A. Wilden, G. Modolo, F. Sadowski, M. Gerdes and D. Bosbach, Solv. Extr. Ion Exch., 2017, 35, 161-173.

16. E. Buncel and I.-H. Um, Tetrahedron, 2004, 60, 7801-7825.

17. G. Klopman, Tetrahedron, 1970, 26, 4549-4554.

18. J. Clayden, N. Greeves and S. Warren, Organic chemistry, Oxford : Oxford University Press, $2^{\text {nd }}$ edn., 2012.

19. M. J. Hudson, L. M. Harwood, D. M. Laventine and F. W. Lewis, Inorg. Chem., 2013, 52, 3414-3428.

20. P. Zsabka, K. Van Hecke, A. Wilden, G. Modolo, M. Verwerft, K. Binnemans and T. Cardinaels, Solv. Extr. Ion Exch., 2020, 38, 194-211.

21. E. Mossini, E. Macerata, A. Wilden, P. Kaufholz, G. Modolo, N. Iotti, A. Casnati, A. Geist and M. Mariani, Solv. Extr. Ion Exch., 2018, 36, 373-386.

22. E. Macerata, E. Mossini, S. Scaravaggi, M. Mariani, A. Mele, W. Panzeri, N. Boubals, L. Berthon, M.-C. Charbonnel, F. Sansone, A. Arduini and A. Casnati, J. Am. Chem. Soc., 2016, 138, 7232-7235.

23. Z. Kolarik, U. Müllich and F. Gassner, Solv. Extr. Ion Exch., 1999, 17, 23-32.

24. A. Geist, U. Müllich, D. Magnusson, P. Kaden, G. Modolo, A. Wilden and T. Zevaco, Solv. Extr. Ion Exch., 2012, 30, 433-444.

25. A. C. Edwards, P. Mocilac, A. Geist, L. M. Harwood, C. A. Sharrad, N. A. Burton, R. C. Whitehead and M. A. Denecke, Chem. Commun., 2017, 53, 50015004.

26. J. M. Muller and K. L. Nash, Solv. Extr. Ion Exch., 2016, 34, 322-333.

27. P. Zsabka, K. Van Hecke, L. Adriaensen, A. Wilden, G. Modolo, M. Verwerft, K. Binnemans and T. Cardinaels, Solv. Extr. Ion Exch., 2018, 36, 519-541.

28. P. Zsabka, K. Van Hecke, A. Wilden, G. Modolo, M. Hupert, V. Jespers, S. Voorspoels, M. Verwerft, K. Binnemans and T. Cardinaels, Solv. Extr. Ion Exch., 2020, 38, 212-235.

29. N. T. Coogan, M. A. Chimes, J. Raftery, P. Mocilac and M. A. Denecke, J. Org. Chem., 2015, 80, 8684-8693.

30. M. C. Nielsen, A. F. Larsen, F. H. Abdikadir and T. Ulven, Eur. J. Med. Chem., 2014, 72, 119-126. 
31. A. Ossola, E. Macerata, E. Mossini, M. Giola, M. C. Gullo, A. Arduini, A. Casnati and M. Mariani, J. Radioanal. Nucl. Chem., 2018, 318, 2013-2022.

32. J.-L. M. Abboud, C. Foces-Foces, R. Notario, R. E. Trifonov, A. P. Volovodenko, V. A. Ostrovskii, I. Alkorta and J. Elguero, Eur. J. Org. Chem., 2001, 16, 3013-3024.

33. V. Ji Ram, A. Sethi, M. Nath and R. Pratap, in The Chemistry of Heterocycles, eds. V. Ji Ram, A. Sethi, M. Nath and R. Pratap, Elsevier, 2019, DOI: https://doi.org/10.1016/B978-0-08-101033-4.00005-X, pp. 149-478.

34. A. R. Katritzkyt and A. F. Pozharskii, Handbook of Heterocyclic Chemistry, Pergamon Press, Oxford, Second edn., 2000.

35. J. M. Muller, S. S. Galley, T. E. Albrecht-Schmitt and K. L. Nash, Inorg. Chem., 2016, 55, 11454-11461. 